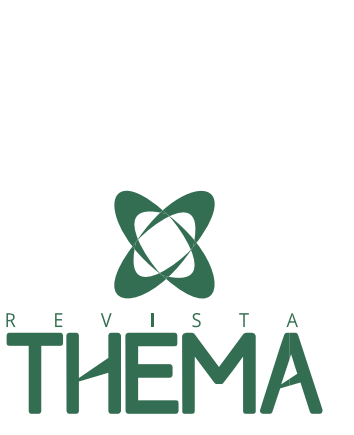

\title{
Tempestade Cerebral, Phillips 66 e GV/GO: a prática com estratégias de ensino em uma turma de curso técnico
}

\section{Cerebral Storm, Phillips 66 and GV/GO: practice with teaching strategies in a technical}

Michele Roos Marchesan ${ }^{1}$; Malcus Cassiano Kuhn'ㄹ Naiara Dal Molin ${ }^{1}$; Helena Miranda da Silva Araújo ${ }^{1}$

\begin{abstract}
RESUMO
O presente relato de experiência versa sobre estratégias de ensino, diferentes das usualmente utilizadas, que foram aplicadas em uma turma de estudantes do curso Técnico em Multimeios Didáticos do Programa Profuncionário, ofertado por um Instituto Federal de Educação, Ciência e Tecnologia do interior do Rio Grande do Sul. As estratégias de ensino utilizadas foram: Tempestade Cerebral, Phillips 66, GV/GO e de avaliação. O referencial teórico que embasa este trabalho está ancorado em Moran (2012), Gil (2015) e Anastasiou e Alves (2003). Por meio da prática, foi possível observar o desconhecimento por parte dos estudantes em relação às estratégias utilizadas e o potencial do seu uso a fim de mobilizar diferentes operações de pensamento, conhecimentos e atitudes por parte dos estudantes e do próprio professor. Ressaltando para este último, a sua função de estrategista.
\end{abstract}

Palavras-chave: Estratégias de Ensino; Tempestade cerebral; Phillips 66; GV/GO; Técnico em multimeios didáticos.

\begin{abstract}
The present experience report is about teaching strategies, different from those usually used, which were applied in a class of students of the Technical Course in Multicultural Didactics of the Profuncionário Program, offered by a Federal Institute of Education, Science and Technology of the interior of Rio Grande do Sul. The teaching strategies used were: Cerebral Storm, Phillips 66, GV / GO and assessment. The theoretical framework that supports this work is anchored in Moran (2012), Gil (2015) and Anastasiou and Alves (2003). Through the practice, it was possible to observe students' lack of knowledge regarding the strategies used and the potential of their use in order to mobilize different operations of thought, knowledge and attitudes on the part of the students and the teacher himself. Highlighting for the latter, his role as strategist.
\end{abstract}

Keywords: Teaching strategies; Brain storm; Phillips 66; GV / GO; Technician in didactic multimedia.

\footnotetext{
${ }^{1}$ IFSul - Instituto Federal de Educação, Ciência e Tecnologia Sul-rio-grandense, Lajeado/RS - Brasil.
} 


\section{CONTEXTUALIZAÇÃO}

Este relato de experiência versa sobre a utilização de diferentes estratégias de ensino aplicadas na turma de estudantes do curso Técnico em Multimeios Didáticos do Programa Profuncionárioi, no mês de agosto do ano de 2016. Utilizou-se as seguintes estratégias de ensino: Tempestade Cerebral, Phillips 66, GV/GO e de avaliação. O desenvolvimento dessa experiência didática se deu a partir dos estudos de referenciais teóricos sobre a temática, segundo o contexto da organização e planejamento do fazer pedagógico, perpassando pelas metodologias didáticas na docência da educação básica ao ensino superior.

"Para onde estamos caminhando no ensino?", esta é a pergunta que Moran (2012, p. 11) nos lança. Antes de avançar por esse caminho, cabe ponderar que a educação, ao longo dos tempos, tem enfrentado diferentes desafios. Contudo, ensinar e aprender ainda são os maiores, sobretudo, neste momento de transição para um modelo de gestão da informação e do conhecimento (Moran, 2012). Nesse sentindo, concorda-se com a afirmação de que, atualmente, "perdemos tempo demais, aprendemos muito pouco, desmotivamo-nos continuamente" (Ibidem, p. 11).

A intenção, portanto, deste relato é apontar, a partir das estratégias de ensino escolhidas e aplicadas, pistas de possíveis caminhos para um ensino com ênfase na aprendizagem dos estudantes. $E$, dentro dessa esfera, ressalta-se que "[...] o papel predominante do professor deixa de ser o de ensinar, e passa a ser o de ajudar o aluno a aprender" (Gil, 2015, p. 7). Dessa forma, indagações como "Quais as expectativas dos alunos?, Em que medida determinado aprendizado poderá ser significativo para eles?, Quais estratégias são mais adequadas para facilitar seu aprendizado?" (Ibidem, p. 7) expressam as preocupações básicas desse professor.

A situação de aprendizagem envolveu uma turma, formada por oito estudantes, do curso Técnico em Multimeios Didáticos do Programa Profuncionário, ofertado por um Instituto Federal de Educação, Ciência e Tecnologia do interior do Rio Grande do Sul. As falas dos estudantes foram gravadas e transcritas para análise dos dados produzidos e, para garantir o anonimato dos sujeitos envolvidos, estes serão aqui denominados por E1, E2 e assim sucessivamente, até E8.

O referido curso é oferecido na modalidade de ensino semipresencial. Uma vez por semana os estudantes frequentam aulas presenciais, mediadas por um tutor presencial. Além desses momentos, os estudos são complementados a distância, por meio de um ambiente virtual de aprendizagem (AVA). Durante os momentos presenciais, em função da metodologia do curso, eventualmente, são propostas pelos professores a distância atividades que promovem a interação entre os estudantes.

Tendo em vista que a turma estava em fase de conclusão do curso técnico, percebeu-se que discutir sobre o que os concluintes pensam sobre as competências do Técnico em Multimeios Didáticos e qual a sua importância no processo educativo nas instituições de ensino, seria de suma importância como forma de encaminhamento para o encerramento do curso.

Para tanto, foram escolhidas e aplicadas as estratégias: Tempestade Cerebral, Phillips 66 e Grupo de verbalização e de observação (GV/GO). A proposta de trabalho apresentada solicitava a escolha e aplicação de duas estratégias. No entanto, durante o planejamento da situação de aprendizagem, sentiu-se necessidade de aplicar uma terceira estratégia e um instrumento avaliativo. Este último configurou-se em um questionário on-line com a finalidade de avaliar e receber feedback dos estudantes em relação à experiência. 


\section{ABORDAGEM TEÓRICA}

Com vistas ao planejamento da situação de aprendizagem tomou-se por base estudiosos que têm se debruçado sobre o tema estratégias de ensino. Sobretudo, aqueles que apontam possíveis caminhos para um ensino com ênfase na aprendizagem dos estudantes.

Como já assinalado, ensinar e aprender ainda são os maiores desafios da educação (Moran, 2012). $\mathrm{E}$, preocupações com as expectativas dos estudantes, em como tornar a aprendizagem significativa e quais estratégias fazer uso a fim de facilitar a aprendizagem (Gil, 2015) ocupam o professor nos momentos de planejamento, realização e avaliação de situações de aprendizagem. Diante disso, percebe-se que o professor "[...] deverá ser um verdadeiro estrategista [...]" (Anastasiou; Alves, 2003, p. 69).

Em face do exposto, adota-se, no presente trabalho, o termo estratégia "[...] no sentido de estudar, selecionar, organizar e propor as melhores ferramentas facilitadoras para que os estudantes se apropriem do conhecimento" (Anastasiou; Alves, 2003, p. 69). A partir dessa perspectiva e que por meio "[...] das estratégias aplicam-se ou exploram-se meios, modos, jeitos, formas, de evidenciar o pensamento, portanto, respeitando às condições favoráveis para se executar ou fazer algo" (Ibidem, p. 70) é que optou-se, no momento do planejamento da situação de aprendizagem, por fazer uso da Tempestade Cerebral, Phillips 66 e Grupo de verbalização e de observação (GV/GO).

Para o planejamento da prática, partiu-se das ideias de Anastasiou e Alves (2003), apresentadas na sequência, em forma de quadros. Em cada quadro estão postas a descrição e a dinâmica de cada estratégia.

No Quadro 1, descreve-se a atividade Tempestade Cerebral, com base em Anastasiou e Alves (2003):

Quadro 1. Estratégia: Tempestade Cerebral

\begin{tabular}{|c|l|}
\hline DESCRIÇÃO & $\begin{array}{l}\text { É uma possibilidade de estimular a geração de novas ideias de forma espontânea } \\
\text { e natural, deixando funcionar a imaginação. Não há certo ou errado. Tudo o que } \\
\text { for levantado será considerado, solicitando-se, se necessário, uma explicação } \\
\text { posterior do estudante. }\end{array}$ \\
\hline $\begin{array}{c}\text { DINÂMICA DA } \\
\text { ATIVIDADE }\end{array}$ & $\begin{array}{l}\text { Ao serem perguntados sobre uma problemática, os estudantes devem: } \\
\text { 1. expressar em palavras ou frases curtas as ideias sugeridas pela questão } \\
\text { proposta. } \\
\text { 2. evitar atitude crítica que levaria a emitir juízo e/ou excluir ideias. } \\
\text { 3. registrar e organizar a relação de ideias espontâneas. }\end{array}$ \\
\hline
\end{tabular}

Fonte: Anastasiou; Alves, 2003, p. 82.

A Tempestade Cerebral, além de ser utilizada com o intuito de levantar hipóteses diante de uma problemática, também pode ser aplicada como fonte de mobilização, pois "[...] desperta nos estudantes uma rápida vinculação com o objeto de estudo [...]" (Anastasiou; Alves, 2003, p. 82).

Já a dinâmica Phillips 66, trata-se de uma atividade de análise e discussão rápida, conforme descrito no Quadro 2: 
Quadro 2. Estratégia: Phillips 66

\begin{tabular}{|c|l|}
\hline DESCRIÇÃO & $\begin{array}{l}\text { É uma atividade grupal, onde são feitas uma análise e discussão sobre temas/ } \\
\text { problemas do contexto dos estudantes. Pode também ser útil para obtenção de } \\
\text { informação rápida sobre interesses, problemas, sugestões e perguntas. }\end{array}$ \\
\hline $\begin{array}{c}\text { DINÂMICA DA } \\
\text { ATIVIDADE }\end{array}$ & $\begin{array}{l}\text { 1. Dividir os estudantes em grupos de } 6 \text { membros, que durante } 6 \text { minutos podem } \\
\text { estar discutindo um assunto, tema, problema na busca de uma solução ou síntese } \\
\text { final ou provisória. A síntese pode ser explicitada durante mais } 6 \text { minutos. } \\
\text { Como suporte para discussão nos grupos, pode-se tomar por base um texto ou, } \\
\text { simplesmente, o aporte teórico que o estudante já traz consigo. } \\
\text { 2. Preparar a melhor forma de apresentar o resultado do trabalho, onde todos os } \\
\text { grupos possam explicitar o resultado pelo seu representante. }\end{array}$ \\
\hline
\end{tabular}

Fonte: Anastasiou; Alves, 2003, p. 87.

Ainda segundo Anastasiou e Alves (2003), a estratégia apresentada no Quadro 2 pode ser utilizada tanto para momentos de mobilização como também para elaboração de sínteses. Uma característica importante da Phillips 66 consiste na estimulação da objetividade por parte dos estudantes, visto que são previamente estipulados o número de integrantes, o tempo para discussão e o tempo para socialização.

Por fim, descreve-se, no Quadro 3, a terceira dinâmica utilizada, Grupo de Verbalização e de Observação (GV/GO):

Quadro 3. Estratégia: Grupo de Verbalização e de Observação (GV/GO)

\begin{tabular}{|c|l|}
\hline DESCRIÇÃO & $\begin{array}{l}\text { É a análise de tema/problemas sob a coordenação do professor, que divide os } \\
\text { estudantes em dois grupos: um de verbalização(GV), e outro de observação (GO). } \\
\text { É uma estratégia aplicada com sucesso ao longo do processo de construção do } \\
\text { conhecimento, e nesse caso, requer leituras, estudos preliminares, enfim, um } \\
\text { contato inicial com o tema. }\end{array}$ \\
\hline $\begin{array}{c}\text { DINÂMICA DA } \\
\text { ATIVIDADE }\end{array}$ & $\begin{array}{l}\text { 1. Dividir os estudantes em dois grupos. Um para verbalização de um } \\
\text { tema/problema e outro de observação. } \\
\text { 2. Organizá-los em dois círculos: um interno e outro externo, dividindo o número } \\
\text { de membros conforme o número de estudantes da turma. Em classes muito } \\
\text { numerosas o grupo de observação será numericamente maior que o de } \\
\text { verbalização. } \\
\text { 3. Num primeiro momento, o grupo interno verbaliza, expõe, discute o tema; } \\
\text { enquanto isto, o GO observa, registra conforme a tarefa que Ihe tenha sido } \\
\text { atribuída. Em classes muito numerosas, as tarefas podem ser diferenciadas, para } \\
\text { grupos destacados na observação. } \\
\text { 4. Fechamento: o GO passa a oferecer sua contribuição, conforme a tarefa que Ihe } \\
\text { foi atribuída, ficando o GV na escuta. } \\
\text { 5. Em classes com menor número de estudantes, o grupo externo pode trocar de } \\
\text { lugar e mudar de função - de observador para verbalizador. } \\
\text { 6. Divide-se o tempo conforme a capacidade do tema em manter os estudantes } \\
\text { mobilizados. } \\
\text { 7. O fechamento, papel fundamental do docente, deve contemplar os objetivos, } \\
\text { portanto, incluir elementos do processo e dos produtos obtidos. }\end{array}$ \\
\hline
\end{tabular}

Fonte: Anastasiou; Alves, 2003, p. 88.

De acordo com as autoras,

[...] essa dinâmica dá melhores resultados se utilizada para o momento de síntese, pois exige dos participantes inúmeras operações de pensamento tais como: análise, 
interpretação, crítica, obtenção e organização de dados, comparação, resumo, observação, etc. (Anastasiou; Alves, 2003, p. 88).

Por tudo isso, é que optou-se por esta estratégia para discussão e análise das competências do Técnico em Multimeios Didáticos e sobre a sua importância no processo educativo nas instituições de ensino, com estudantes que se encontram na condição de concluintes do curso técnico.

\section{DETALHAMENTO DAS ESTRATÉGIAS E ANÁLISE}

A situação de aprendizagem foi desenvolvida basicamente em quatro momentos: vivências das estratégias Tempestade Cerebral, Phillips 66, Grupo de Verbalização e de Observação (GV/GO) e avaliação da experiência pedagógica.

\subsection{Estratégia Tempestade Cerebral}

A situação de aprendizagem iniciou com a utilização da estratégia Tempestade Cerebral, tendo por objetivo principal mobilizar os conhecimentos prévios dos estudantes acerca do papel do Técnico em Multimeios Didáticos no ambiente escolar. Para isso, lançou-se o questionamento mobilizador: "Diante do que vocês já viram, leram e estudaram até aqui, expressem em uma palavra qual o papel do Técnico em Multimeios Didáticos no ambiente escolar?".

À medida que as palavras emergiram, foram registradas no quadro para posterior leitura e discussão. Como referenciado anteriormente, a dinâmica em questão, quando utilizada como mobilização, ativa nos estudantes uma ágil vinculação com o tema em estudo (Anastasiou; Alves, 2003).

No centro do quadro escreveu-se Técnico em Multimeios Didáticos e rapidamente surgiram as palavras e/ou expressões: mediador; computador; tecnologias; multi setores; auxilia nos multimeios; auxilia nos diversos ambientes e laboratórios; conhecimento através da tecnologia; pesquisador; mais educadora. A imagem do quadro pode ser visualizada conforme Figura 1.

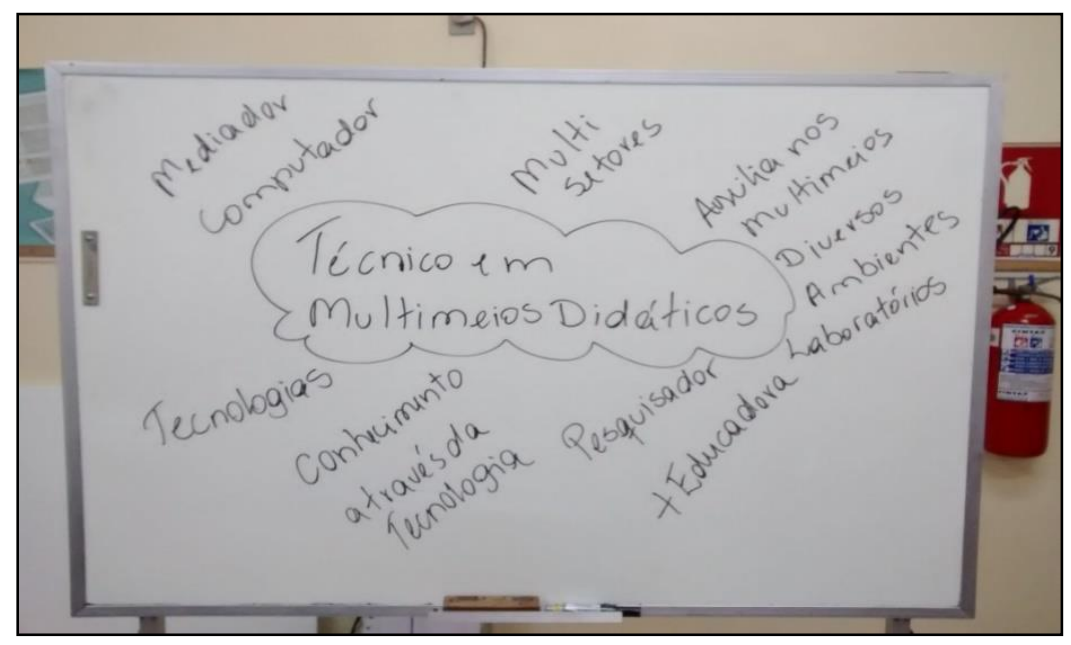

Figura 1. Imagem do quadro com o registro das palavras e/ou expressões Fonte: Elaborado pelos estudantes, 2016.

Com essa estratégia foi possível, além da vinculação com o tema, contar com a contribuição individual de cada estudante diante do coletivo. Nela, "[...] a expressão verbal do aluno é desenvolvida diante de todos os colegas, levando-o a se expor às habituais críticas dos outros. Esse é um aspecto a ser considerado pelo professor, como um objetivo atitudinal a ser desenvolvido" (Anastasiou; Alves, 2003, p. 75). Diante disso, as autoras ressaltam a importância do clima de acolhimento por parte do 
professor quando recebe e aceita a contribuição de cada estudante, fato essencial quando se busca processos coletivos de construção de conhecimentos (Ibidem).

Em seguida, foi realizada uma rápida leitura das palavras e/ou expressões e prosseguiu-se para a dinâmica Phillips 66.

\subsection{Estratégia Phillips 42}

Tendo em vista que as estratégias respeitam as condições de execução (Anastasiou; Alves, 2003), na proposta utilizada realizou-se uma adaptação, passando a denominar a atividade de Phillips 42. Com o objetivo de ler e discutir uma charge que retrata uma situação do cotidiano escolar (Figura 2), a turma foi dividida em quatro duplas. A formação das duplas deu-se por meio de um quebracabeça, momento em que cada estudante precisou procurar e montar um quebra-cabeça, e, com isso, formou-se a imagem de uma charge (Figura 2).

As quatro duplas, em dois minutos, discutiram as ideias surgidas a partir da charge. Posteriormente, cada dupla compartilhou, novamente durante dois minutos, as leituras que realizaram da charge.

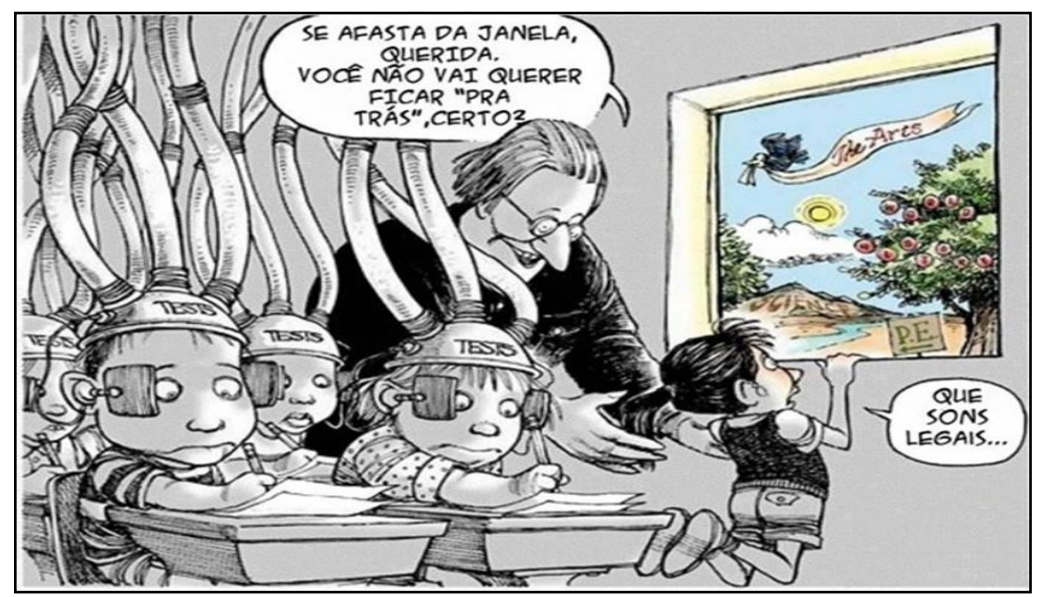

Figura 2. Charge utilizada como suporte para a Phillips 42

Fonte: Coletado pelos autores, 2016.

A charge retrata uma cena, muitas vezes, comum no ambiente escolar, e, nesse sentido, discutir sobre a situação apresentada mostrou-se de suma importância. Tendo em vista que é no cotidiano escolar que o Técnico em Multimeios Didáticos realizará o seu papel enquanto profissional da educação, refletir sobre o que se passa na escola apresenta-se como fundamental para o exercício da profissão.

A seguir, destacam-se algumas falas que evidenciam as leituras realizadas pelos estudantes em relação à charge (Figura 2):

A primeira coisa que nos veio a mente foi a menininha na janela e a professora querendo que ela ficasse igual aos outros. Ela foi em busca do novo e a professora não se deu conta de que ela poderia abstrair dessa menina mais conhecimento do que o tradicional, porque ela está buscando alguma coisa diferente. (E8)

Como na sala de aula tradicional tudo é sem graça, sem cor e o que está lá fora é muito mais atrativo e colorido, quer dizer então que existiria uma nova possibilidade de ensinar, uma outra forma de tornar interessante para o aluno. (E2)

Eu entendi que na sala de aula a maioria segue a orientação da professora, mas toda sala de aula tem um diferente que não se adapta ao ritmo da professora. (E7) 
Percebeu-se durante a realização da atividade que os estudantes conseguiram em curto espaço de tempo analisar, interpretar e até mesmo criticar o cotidiano apresentado por meio da charge. Além disso, foi necessário que cada dupla exercitasse a objetividade tanto no momento de discussão nas duplas quanto no compartilhamento com as demais duplas.

\subsection{Estratégia Grupo de Verbalização e de Observação (GV/GO)}

Com o intuito de discutir sobre as competências específicas do Técnico em Multimeios Didáticos e a sua importância no processo educativo das escolas utilizaram-se, como fios condutores da atividade, dois textos que versam sobre o tema. Inicialmente, os estudantes foram divididos em dois grupos com quatro integrantes.

Antes do início da atividade e para a divisão dos grupos, ofereceram-se dois tipos de bombons. A partir das escolhas dos estudantes, constituíram-se os grupos. Em seguida, cada grupo realizou a leitura de um dos textos. A opção pelo uso de dois textos distintos deu-se em função de serem complementares, e, também, para possibilitar que todos os estudantes participassem do GV (grupo de verbalização) e do GO (grupo de observação).

Depois da leitura dos textos nos grupos, foram vivenciados dois momentos de discussões, cada momento com diferentes definições de papéis e objetivos de explanações. As orientações dadas a cada grupo são descritas no Quadro 4:

Quadro 4. Orientações para execução da estratégia GV/GO

\begin{tabular}{|c|c|}
\hline $\begin{array}{l}\qquad 10 \text { Grupo de Verbalização: } \\
\text { - Objetivo do grupo: discutir sobre a importância dos } \\
\text { funcionários no processo educativo das escolas. } \\
\text { Definição de papéis: facilitador, reloginho (controlador do } \\
\text { tempo). Atenção: cuidem para não revelarem os papéis! } \\
\text { · Durante a discussão: O grupo deverá seguir as } \\
\text { orientações do facilitador e do reloginho, mas não deverão } \\
\text { demonstrar a quem estes papéis se referem. } \\
\text { Tempo de discussão: quatro minutos. }\end{array}$ & $\begin{array}{l}\qquad 10 \text { Grupo de Observação: } \\
\text { Objetivo do grupo: realizar observação da atividade como } \\
\text { um todo: } \\
\text { - participação dos integrantes - todos participaram? } \\
\text { - como foi a condução da discussão? } \\
\text { - qual o tema abordado na discussão? } \\
\text { - como foi o aproveitamento e controle do tempo? } \\
\text { Após, o grupo apresentará os aspectos observados. } \\
\text { Te Tempo para apresentação: dois minutos. }\end{array}$ \\
\hline $\begin{array}{l}\qquad 2^{\circ} \text { Grupo de Verbalização: } \\
\text { Objetivo do grupo: Discutir as competências específicas do } \\
\text { Técnico em Multimeios Didáticos e apresentar sugestões } \\
\text { de ações no auxílio e suporte à ação educativa. } \\
\text { Definição dos papéis: facilitador (terá a função de } \\
\text { coordenar a discussão, organizar as falas e controlar o } \\
\text { tempo). Atenção: cuidem para não revelar o papel! } \\
\text { Tempo de discussão: quatro minutos. }\end{array}$ & $\begin{array}{l}\text { - } 20 \text { Grupo de Observação: } \\
\text { como um todo: } \\
\text { - participação dos integrantes - todos participaram? } \\
\text { - como foi a condução da discussão? } \\
\text { - qual o tema abordado na discussão? } \\
\text { - como foi o aproveitamento e controle do tempo? } \\
\text { Após, o grupo apresentará os aspectos observados. } \\
\text { Tempo para apresentação: dois minutos. }\end{array}$ \\
\hline
\end{tabular}

Fonte: Elaborado pelos autores, 2016.

A seguir, ressaltam-se excertos do diálogo do primeiro GV:

- O texto busca demonstrar a importância de todos os funcionários, desde as merendeiras na hora do lanche até o pessoal da limpeza [...]. (E2)

- O funcionário vai estar auxiliando na questão das atitudes, na postura. Ele vai estar acrescentando conhecimento ao aluno. E também, isso já está previsto na LDBEN. Os 
profissionais da educação são os professores, são os trabalhadores da educação, os portadores de diploma de pedagogia e também de curso técnico ou superior em área pedagógica ou afim. Quer dizer que a nossa função enquanto funcionário de escola, seja ela de secretário, merendeiro, bibliotecário, está previsto na lei. E a gente tem que se sentir integrante disso. Se sentir um profissional da educação [...]. (E4)

- [...] Tu tem que se vê como integrante da educação e perceber a tua importância dentro da escola. (E2)

- [...] O funcionário tem que atuar, ser integrante dentro da escola, opinar, dar sugestões. (E6)

- [...] Com esta profissionalização, os funcionários vão se sentir, assim como nós, mais seguros para dar sugestões, dar opinião. (E2)

- Por isso que no final até consta também da importância do Programa do Profuncionário, porque ele vem agregando conhecimento e fazendo com que os funcionários de escola se sintam valorizados e sintam sua importância no ambiente escolar. (E4)

Após a discussão do primeiro GV, o primeiro GO expôs seus apontamentos. Na sequência, destacamse excertos do diálogo:

- Acho que ficaram dentro do tempo. (E7)

- Todas falaram. (E3)

- Acho que a E1 era a mediadora, a facilitadora. [...] O assunto era a importância do funcionário.(E7)

- A valorização do funcionário, a importância dos funcionários na escola. (E8)

Dando seguimento, passou-se para uma segunda execução de GV e GO, momento em que houve a troca dos membros do GV e GO. Salientam-se, a seguir, momentos das discussões dos dois grupos. Inicialmente, o GV:

- A gente sabe que dentro da escola tem vários papéis, [...] mas agora nos formando em técnicos a gente consegue já agir de uma forma mais segura. Como a gente trabalha na biblioteca, a gente tem um campo mais amplo para auxiliar. A biblioteca abrange todos os sistemas da escola. (E8)

- Eu acho que a gente se sente agora com um conhecimento mais histórico da questão da educação, tendo uma visão tão ampla do nosso fazer. (E7)

- [...] Podendo auxiliar na gestão da escola, nas decisões. [...] O conhecimento das tecnologias que a gente não tinha [...].(E3)

- Todos os campos que a gente aprendeu aqui, as atividades do técnico nos remetem a auxiliar os professores de alguma forma, então quando nós buscamos outras alternativas, por exemplo, e auxiliamos os professores com suas atividades. (E8)

- [...] Tornando a aula mais rica, mais criativa. Uma leitura na pracinha. (E5)

- Isso, a importância de trocar de ambiente, de sair da sala de aula. [...] A importância da participação da comunidade também tem que ser valorizado. (E7)

Na continuidade da estratégia, o segundo GO:

- O tema eu acho que era o papel... (E1)

- Era dos multimeios mais específicos, elas enfocaram. (E4)

- A gente está sendo formado para isso. (E6)

Durante a realização da estratégia observou-se que os estudantes discutiram não somente as ideias apresentadas nos textos disponibilizados, mas também muito do que já haviam estudado anteriormente. Conseguiram realizar análise crítica da realidade dos funcionários na escola, de uma 
forma ampla, mas também, acentuaram o perfil e a importância do Técnico em Multimeios Didáticos, construindo um importante momento de síntese.

Alguns estudantes manifestaram-se um pouco mais, outros um pouco menos. Aspecto a ser considerado em um futuro planejamento. A partir desses levantamentos,

Pontuamos que as estratégias grupais constituem-se num desafio a ser reconhecido e enfrentado. Sabemos que a aprendizagem é um ato social, necessitando da mediação do outro como facilitador do processo; esse outro que estabelece a mediação entre o aluno e o objeto de estudo pode ser o professor, os colegas ou um texto, um vídeo, um caso a ser solucionado, um tema a ser debatido (Anastasiou; Alves, 2003, p. 75).

Ao término da atividade, alguns estudantes manifestaram opiniões acerca da experiência:

- Como é ruim ficar só ali discutindo com o grupo, quando eu vi já estava olhando para os outros. [...] $\mathrm{E}$ tu vê que as de fora também tem momentos assim que querem compartilhar.(E1)

- [...] Esse é um tema muito amplo. (E5)

- Você tem que ler, discutir, colocar ideias, observar, cuidar do tempo, cuidar dos outros e de quem está te observando. (E3)

- [...] Parece muito com a função do professor. (E8)

Como forma de fechamento das discussões no grande grupo retomou-se as estratégias anteriormente desenvolvidas, e, sobretudo, o registro das ideias surgidas durante a Tempestade Cerebral, uma vez que

[...] uma mesma estratégia pode objetivar perspectivas diferentes. Por exemplo, uma estratégia como a Tempestade Cerebral pode ser utilizada para mobilização, no início de uma unidade. Ela pode também servir como diagnóstico no transcorrer da unidade ou como fechamento no momento final de uma aula ou unidade: aí está a arte docente, em sua função de estrategista (Anastasiou; Alves, 2003, p. 74).

Os estudantes foram novamente convidados para, se necessário fosse, complementarem a Tempestade Cerebral inicial. Assim sendo, surgiram as palavras e/ou expressões: desafiadora; colaborador; mediador; linguagem audiovisual; formação do aluno; profissional da educação. A imagem final dos registros pode ser visualizada na Figura 3.

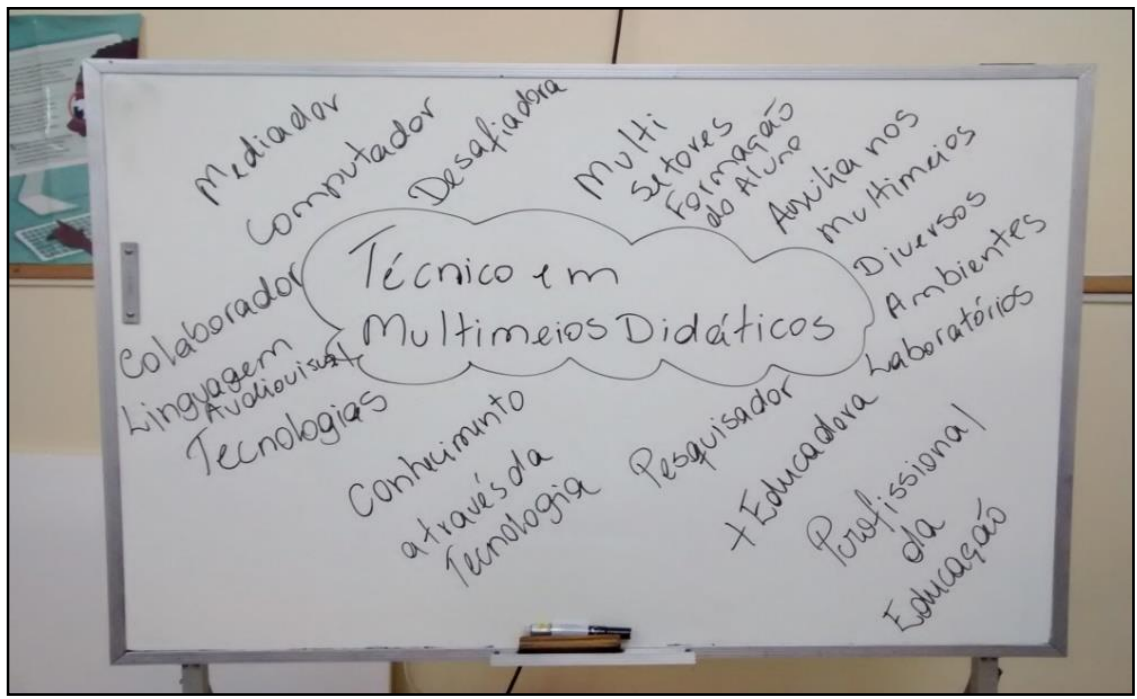

Figura 3. Imagem final dos registros das palavras e/ou expressões

Fonte: Elaborado pelos estudantes, 2016. 
Ainda nesse momento, um estudante fez o seguinte relato:

Eu queria assim fazer um gancho de como me causou uma inquietação quando eu li esse artigo, [...] a gente tem um papel tão importante, não que os outros não tenham. [...] A gente dá tanto apoio para o professor, que fiquei pensando, nossa né.[...] Não tinha ainda me visto ainda assim tão importante. (E2)

Alcançadas essas complementações, partiu-se para avaliação individual da situação de aprendizagem.

\subsection{Instrumento Avaliativo da Situação de Aprendizagem}

Com a finalidade de receber feedback individual de cada estudante em relação à situação de aprendizagem, utilizou-se um questionário on-line com seis questões abertas. Optou-se pelo formato on-line por entender que, por se tratar de um curso Técnico em Multimeios Didáticos, o uso da tecnologia digital faz parte da sua prática profissional.

As perguntas 1 e 2 tratavam dos pontos positivos e negativos da situação de aprendizagem. A questão 3 questionava se os estudantes já conheciam as estratégias utilizadas. Já nas perguntas 4 e 5, eles foram convidados a escrever sobre como se sentiram durante a atividade e se novas aprendizagens ocorreram a partir da situação. Por fim, deixou-se espaço para comentários/sugestões. As questões utilizadas, conforme Quadro 5, foram:

Quadro 5. Relação de questões do questionário on-line aplicado aos estudantes

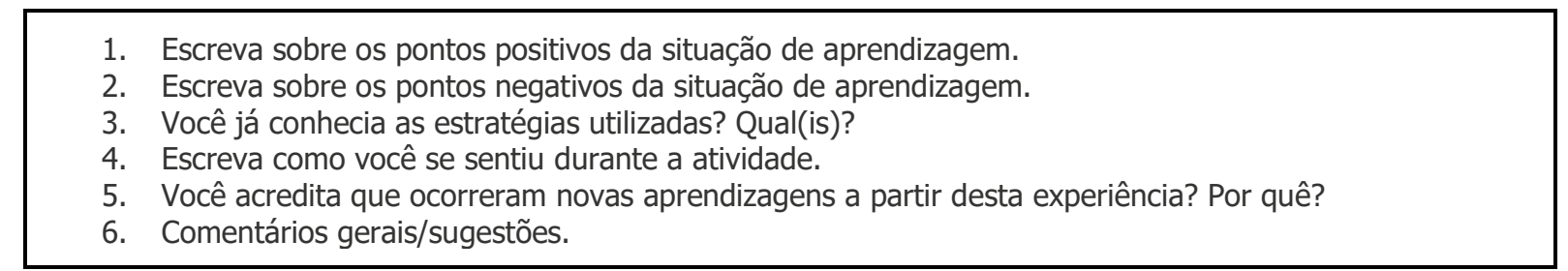

Fonte: Elaborado pelos autores, 2016.

A seguir, mencionam-se algumas das falas dos estudantes em relação aos pontos positivos da situação de aprendizagem:

Reflexão e debate crítico acerca do tema estudado, ampliando a visão inicial acerca do assunto. (E4)

Troca de experiências, discussão em grupo, possibilidade de ver outros pontos de vista. (E2)

Troca de conhecimentos, limitação de tempo, várias atribuições ao mesmo tempo. (E3)

Em relação aos pontos negativos da situação de aprendizagem:

Sentimos um pouco da pressão de falar em público (E7).

Não há. Dificuldade em esperar a vez para manifestar-se, mas isto também tem o seu objetivo e é importante (E4).

Não considero como negativo, mas difícil não poder intervir, interferir no debate (E1).

Das estratégias utilizadas, somente um estudante já conhecia a dinâmica GV/GO. Ao relatar sobre como se sentiram durante a atividade, surgiram as seguintes falas: 
Me senti envolvida com as ideias e importante por ter oportunidade de me pronunciar frente as ideias apresentadas. (E8)

Me senti instigada e inquieta. (E2)

Percebi que é importante organizar-se na fala e com o grupo, evitando repetições, também ser observador, reflexivo a fala dos demais participantes. (E4)

No tocante à ocorrência de novas aprendizagens:

Sim ocorreram. Pois através da troca com os colegas pude rever alguns conceitos e aprofundar outros. (E6)

Sim. Através da troca de experiências com o grupo. Foi um momento rico e de expansão do conhecimento, de modo diferente do habitual. (E4)

Sim, avaliar um assunto dentro de uma proposta de atividade diferente abre ideias para outros assuntos. (E1)

Por fim, alguns comentários/sugestões dos estudantes:

Nunca havia realizado uma atividade parecida. Sugiro que possa se repetir em outros momentos. (E8)

Momento rico com troca de experiências. (E2)

Gostei da técnica com gravuras, já penso em usar em oficinas de leitura. (E1)

A partir das falas destacadas, é possível inferir que os objetivos inicialmente propostos durante o planejamento da situação de aprendizagem foram atingidos. Além disso, também se confirmou que por meio

[...] das estratégias aplicam-se ou exploram-se meios, modos, jeitos, formas, de evidenciar o pensamento, [...]. Esses meios ou formas comportam determinadas dinâmicas, devendo considerar o movimento e as forças, e o organismo em atividade. Por isto, o conhecimento do aluno é essencial para a escolha da estratégia [...] (Anastasiou; Alves, 2003, p. 70).

Outra consideração diz respeito ao destaque dado pelos estudantes para o trabalho em grupo vivenciado durante a prática. As autoras, nesse contexto, reforçam

"[...] a ideia de que trabalhar num grupo é diferente de fazer parte de um conjunto de pessoas, sendo fundamental a interação, o compartilhar [...]. Isto exige autonomia e maturidade, algo a ser construído paulatinamente com os alunos [...] (Anastasiou; Alves, 2003, p. 75-76).

Percebe-se, por um lado, o desconhecimento por parte dos estudantes em relação às estratégias. Por outro lado, foi sugerido que momentos como os experienciados sejam mais frequentes.

\section{CONSIDERAÇÕES FINAIS}

Este relato de experiência pretendeu apontar, por meio da vivência de uma situação de aprendizagem mediada por estratégias de ensino, pistas de possíveis caminhos para um ensino com ênfase na aprendizagem dos estudantes. Para o planejamento da situação, diferentes aspectos foram considerados: o número de estudantes; o tempo disponível; a condição de estudantes concluintes de um curso técnico; o enfoque do curso, já que se tratava de um curso técnico direcionado para formação de profissionais da educação; o propósito de propiciar momentos de exposição individual, interação e trabalho em grupo. Essas preocupações e, consequentemente, as decisões tomadas ressaltam a arte do professor, exercendo sua função de estrategista. 
Pelas falas dos estudantes, percebeu-se que essa situação de aprendizagem, mediada pelas estratégias Tempestade Cerebral, Phillips 66 e GV/GO, propiciou momentos de reflexão sobre a própria prática e evidenciou a importância dos funcionários de escola no contexto escolar. A título de exemplo, destaca-se a exposição espontânea do estudante E2 no momento de fechamento da situação. Em poucos momentos, durante o curso, o estudante se manifestou, salvo às vezes em que foi instigado. Com isso, observa-se o potencial do uso de diferentes estratégias e o quanto é possível mobilizar diferentes operações de pensamento, conhecimentos e atitudes por parte dos estudantes e do próprio professor.

Nesse ponto, destaca-se a importância do professor em estar aberto ao inesperado e, instantaneamente, redirecionar, se necessário for, o seu planejamento. Entende-se que isso é construído ao longo da profissão. Momentos de insegurança e incerteza estarão presentes, assim como esteve enquanto planejou-se e concretizou-se o trabalho aqui relatado.

\section{REFERÊNCIAS}

ANASTASIOU, Léa das Graças Camargos; ALVES, Leonir Pessate (Orgs.). Processos de ensinagem na universidade: pressupostos para as estratégias de trabalho em aula. Joinville: UNIVILLE, 2003.

GIL, Antonio Carlos. Didática do ensino superior. 1. ed. São Paulo: Atlas, 2015.

MORAN, José Manuel. Ensino e aprendizagem inovadores com tecnologias audiovisuais e telemáticas. In: In: MORAN, José Manuel; MASETTO, Marcos T.; BEHRENS, Marilda Aparecida. Novas tecnologias e mediação pedagógica. 19. ed. São Paulo: Papirus, 2012.

\footnotetext{
' Profuncionário: Programa de Formação Inicial em Serviço dos Profissionais da Educação Básica dos Sistemas de Ensino
} Público. 